\title{
MENGATASI MASALAH DISTORSI KOGNITIF PADA KLIEN USIA REMAJA DENGAN METODE COGNITIVE RESTRUCTRING FORM
}

\author{
OLEH: \\ RINI RIZKIAWATI ${ }^{1}$, DESSY HASANAH SITI ASIAH ${ }^{2}$ \\ 1 Mahasiswa Program Studi Kesejahteraan Sosial - Universitas Padjadjaran \\ 2 Staf Pengajar Departemen Kesejahteraan Sosial -Universitas Padjadjaran \\ (email: rizkiarini23@gmail.com, dessyhasanenoch@gmail.com )
}

\begin{abstract}
ASBTRAK
Remaja merupakan suatu masa transisi dari anak-anak menuju dewasa. Mereka cenderung ingin mencari jati dirinya sendiri. Dalam proses tersebut seringkali mereka bertindak tanpa memikirkan dampak dari yang dilakukannya. Subyek penelitian adalah salah satu siswa kelas X SMAN Jatinangor yang memiliki masalah distorsi kognitif. Masalah tersebut berawal dari suasana rumah yang tidak membuatnya nyaman. Sehingga seringkali menimbulkan masalahmasalah baru dalam kehidupan sehari-harinya. Distorsi kognitif sendiri merupakan suatu cara berpikir seseorang yang berlebihan dan tidak rasional terhadap suatu hal atau masalah. Melihat masalah distorsi kognitif tersebut maka diperlukan pendampingan individual ini untuk membantu klien mengatasi permasalahan distorsi kognitifnya. Metode yang akan diberikan adalah dengan menggunakan Cognitif Restructuring Form (CRF). Tujuan pendampingan ini yaitu untuk mengatasi dari masalah distorsi kognitif. Metode tersebut diterapkan selama satu minggu dan hasilnya terlihat adanya perubahan yang baik.
\end{abstract}

Kata Kunci $\quad$ : Remaja, Distorsi Kognitif, Cognitif Restructuring Form (CRF).

\section{HANDLING A COGNITIVE DISTORTION TO CLIENTS} WITH TEENAGER'S COGNITIVE RESTRUCTRING FORM

\begin{abstract}
ABSTRACK
Adolescents is a transition from children to adulthood. They tend to want for finding their own identity. In the process, they often act without considering the impact of their accomplishments. Subjects were one of the students of class X SMAN Jatinangor who have a problem of cognitive distortions. The problem originated from a home atmosphere that does not make them comfortable. So often pose new problems in their daily lives. Cognitive distortions itself is a way of thinking of a person's excessive and irrational to an issue or problem. Seeing the problem of cognitive distortions, so it needs an individual assistance to help clients overcome the problems of cognitive distortion. The method that will be given is to use cognitive Restructuring Form (CRF). The main purpose is to solve the problem of cognitive distortions. The methods are applied for one week and the results are visible changes for the better.
\end{abstract}

Keywords: Teens, Cognitive Distortions, Cognitive Restructuring Form (CRF) 


\section{Pendahuluan ( Introduction)}

Burns (1988) mengungkapkan bahwa perasaan individu sering dipengaruhi oleh apa yang dipikirkan individu mengenai dirinya sendiri. Pikiran individu tersebut belum tentu merupakan suatu pemikiran yang objektif mengenai keadaan yang dialami sebenarnya. Penyimpangan proses kognitif oleh Burns (1988) juga disebut dengan distorsi kognitif. Pemikiran Burns merupakan pengembangan dari pendapat Goldfried dan Davison (1976) yang menyatakan bahwa reaksi emosional tidak menyenangkan yang dialami individu dapat digunakan sebagai tanda bahwa apa yang dipikirkan mengenai dirinya sendiri mungkin tidak rasional, untuk selanjutnya individu belajar membangun pikiran yang objektif dan rasional terhadap peristiwa yang dialami. Bentuk-bentuk distorsi kognitif menurut Burns (1988) yaitu: Over Generalization, Personalization, Dichotomous Thingking, Mind Reading, Magnificantio, Minimazation, Penalaran Emosional, Must Statement dan Ketergantungan. Seperti halnya klien yang memiliki masalah distorsi kognitif. Maka untuk mencapai tujuan dalam proses konseling diperlukan teknik-teknik yang digunakan untuk pengubahan cara berfikir. Salah satunya adalah Cognitive Restructuring Form (CRF).

\section{Cognitive Restructuring Form (CRF)} dapat digunakan untuk meningkatkan aktivitas, menurunkan perilaku yang tidak diinginkan, meningkatkan kepuasan dan meningkatkan kemampuan sosial. Diharapkan dengan menggunakan metode tersebut klien mampu merubah cara berpikirnya yang selalu negatif. Topik penelitian ini dipilih karena dianggap sangat bermanfaat bagi semua kalangan yang selalu berpikir negatif dan tidak rasional terhdap suatu hal atau masalah yang dihadapinya. Sedangkan penelitian ini bertujuan untuk membantu klien dalam upaya menangani permasalahan dan kebutuhan melalui proses pendampingan.

\section{Metode (Methods), Hasil dan Pembahasan} (Results and Discussion)

Setelah itu praktikan mngaitkan masalah klien termasuk dalam masalah kognitif Hal tersebut sangat penting dilakukan agar praktikan mampu untuk menentukan Plant of Treatment dan Treatment yang tepat untuk menyelesaikan masalah yang dimiliki oleh klien. Kemudian klien mulai memberikan suatu metode CRF, karena metode intervensi tersebut dinilai sangat tepat bagi klien dan praktikan pada saat itu. 
Penelitian ini berbasis pada metode kognitif yang mempunyai masalah distorsi kognitif. Hal ini dipilih karena permasalahan yang terjadi pada klien termasuk permasalahan kognitifnya. Praktikan melaksanakan praktikum di SMAN Jatinangor yang dilaksanakan sekitar \pm 3 bulan dengan minimal 1 kali dalam seminggu pertemuan tatap muka langsung bersama klien. Subyek penelitian adalah salah satu murid kelas $\mathrm{X}$ yang direkomendasikan oleh guru BK SMA Negeri Jatinangor.

Penggalian data dan informasi didapatkan melalui interview yang menggunakan 3 instrumen, yaitu asesmen keberfungsian sosial, ecomap dan genogram. Asesmen keberfungsian klien digunakan dengan menggali informasi dari klien, guru BK dan teman-teman klien di sekolah dengan tujuan untuk mengetahui keberfungsian klien di lingkungan sekitarnya. Ecomap digunakan untuk memetakan masalah klien dan melihat hubungan individu di keluarga inti klien, sedangkan genogram digunakan untuk melihat susunan keluarga klien.

Setelah assessment selesai maka praktikan langsung mengaitkan masalah klien termasuk dalam masalah kognitif. Hal tersebut sangat penting dilakukan agar praktikan mampu untuk menentukan Plant of Treatment dan Treatment yang tepat untuk menyelesaikan masalah yang dimiliki klien.

Dalam proses intervensi metode yang digunakan adalah terapi kognitif karena masalah yang dimiliki klien adalah distorsi kognitif. Dalam program intervensi peneliti menggunakan Cognitive Restructuring Form (CRF). Metode tersebut membantu klien untuk merubah cara berpikirnya yang selalu negatif menjadi positif dalam menhadapi suatu hal atau masalah. Berikut tahapan proses praktik yang telah dilakukan oleh praktikan selama proses praktikum berlangsung.

\section{Tabel 1. Tahapan Proses Praktik}

\begin{tabular}{|l|l|l|}
\hline \multicolumn{1}{|c|}{ Tanggal } & \multicolumn{1}{c|}{ Aktivitas } & \multicolumn{1}{c|}{ Tempat } \\
\hline 1 April 2016 & Kontak awal dengan klien & Ruang BK SMA Negeri Jatinangor \\
\hline 8 April 2016 & Inform Concent dengan klien & Ruang BK SMA Negeri Jatinangor \\
\hline 15 April 2016 & Kontrak dengan klien & Ruang BK SMA Negeri Jatinangor \\
\hline 22 April 2016 & Assessment 1 & Mesjid SMA Negeri Jatinangor \\
\hline 29 April 2016 & Assessment 2 & Mesjid SMA Negeri Jatinangor \\
\hline 13 Mei 2016 & Assessment 3 & Mesjid SMA Negeri Jatinangor \\
\hline 27 Mei 2016 & Plan of Treatment & Mesjid SMA Negeri Jatinangor \\
\hline 3 Juni 2016 & Treatment & Mesjid SMA Negeri Jatinangor \\
\hline 10 Juni 2016 & Terminasi & Mesjid SMA Negeri Jatinangor \\
\hline 15 Juni 2016 & Evaluasi & Mesjid SMA Negeri Jatinangor \\
\hline
\end{tabular}


Hasil dan Pembahasan (Results and Discussion)

Lokasi dimana praktikan dan klien biasa bertemu adalah di SMAN Jatinangor, tepatnya di mesjid sekolah. Hal ini didasari dengan pertimbangan agar kami dapat bertemu dalam jam pelajaran BK. Karena praktikan melakukan sesi konseling saat adanya jadwal mata pelajaran BK di kelas klien. Hal ini didasari atas saran guru BK sekolah tersebut dan ditentukan oleh pihak sekolah yang tidak ingin terjadi suatu masalah jika siswanya dibimbing di luar sekolah. Praktikan dan klien melakukan konseling di Mesjid SMA Negeri jatinangor. Menurut klien mesjid tempat yang sepi saat itu dan membuat klien nyaman saat konseling berlangsung. Kemudian klien lebih bisa leluasa untuk bercerita meskipun terkadang ada temannya yang mau beribadah solat. Sehingga klien sering merasa malu atau terkadang terdiam dan mengakibatkan pikirannya terbagi-bagi antara bimbingan dan melihat teman-temanya yang berada di sekitar tempat klien berlangsung konseling. Namun, klien tetap menyetujui jika bimbingan konselingnya dilakukan melalui media sosial

\section{Tabel 2. Kekurangan dan Kelebihan Klien}

\begin{tabular}{|c|c|c|c|c|}
\hline Nama & Kelebihan & Kekurangan & $\begin{array}{c}\text { Masalah (Jika } \\
\text { Ada) }\end{array}$ & $\begin{array}{c}\text { Aspek-aspek } \\
\text { pribadi yang ingin } \\
\text { di kembangkan }\end{array}$ \\
\hline A.F & $\begin{array}{l}\text { - Bermain sepak bola } \\
\text {-Mudah bergaul }\end{array}$ & $\begin{array}{l}\text {-Suka bermain } \\
\text { hingga larut } \\
\text { malam } \\
\text {-Kurang bisa } \\
\text { mengatur } \\
\text { emosinya }\end{array}$ & $\begin{array}{l}\text { - Suka bolos } \\
\text { sekolah } \\
\text {-Bermain hingga } \\
\text { larut malam } \\
\text {-Bertengkar } \\
\text { dengan ayahnya }\end{array}$ & $\begin{array}{l}\text {-Tidak bermain } \\
\text { hingga larut malam } \\
\text {-Ingin lebih } \\
\text { mengontrol dirinya } \\
\text { agar tidak emosian } \\
\text { - Tidak sering bolos } \\
\text { sekolah }\end{array}$ \\
\hline
\end{tabular}

Berdasarkan kesepakatan praktikan dengan klien permasalahan yang akan dibantu diselesaikan oleh pekerja sosial adalah mengurangi cara berfikir klien yang selalu negatif terhadap suatu masalah yang ia hadapi. Sifat tersebut sangat perlu untuk diperbaiki karena diakui oleh klien sifat negatifnya tersebut sangat mempengaruhi kehidupannya dan menimbulkan dampak yang buruk. Salah satu dampaknya adalah prestasi akademik klien yang semakin menurun karena sering membolos. Klien pun menjadi tidak mempunyai hubungan yang harmonis dengan ayah dan kakak tirinya. Klien ingin memperbaiki hubungan dengan ayah dan kakak tirinya agar dia dapat 
bersama kembali dan saling menyapa ketika di rumah seperti sebelum masalah tersebut terjadi. Sebenarnya klien lebih memilih bermain dengan temannya hingga larut malam dibandingkan di rumahnya. Hal tersebut terjadi karena dia merasa tidak nyaman ketika berada di rumahnya. Ayahnya sering memarahinya hingga dipukul dan mebanding-bandingkan dirinya dengan kakak tirinya. Alasan penting praktikan memilih kasus ini untuk ditangani adalah karena distorsi kognitif atau kesalahan cara berpikir klien yang mempengaruhi perilaku klien.

\section{Tabel 3. Cognitive Restructuring Form Yang Telah Diisi Oleh Klien}

\begin{tabular}{|c|c|c|c|c|}
\hline $\begin{array}{l}\text { Situasi/kejadian } \\
\text { tulis secara ringkas } \\
\text { kejadian } \\
\text { FAKTUAL yang } \\
\text { menimbulkan } \\
\text { emosi yang tidak } \\
\text { menyenangkan }\end{array}$ & $\begin{array}{l}\text { EMOSI } \\
\text { Ditentukan: } \\
\text { Sedih/cemas/m } \\
\text { arah dll. } \\
\text { Skor kadar } \\
\text { emosi: } 1-100 \%\end{array}$ & $\begin{array}{l}\text { Fikiran-fikiran } \\
\text { otomatis self talk } \\
\text { yang } \\
\text { menyebabkan } \\
\text { emosi }\end{array}$ & $\begin{array}{l}\text { Tanggapan } \\
\text { rasional/debat } \\
\text { terhadap pemikiran } \\
\text { otomatis }\end{array}$ & $\begin{array}{l}\text { Respon } \\
\text { emosional yang } \\
\text { baru skor kadar } \\
\text { emosi yang baru } \\
\text { secara berurutan } \\
0-100 \%\end{array}$ \\
\hline $\begin{array}{l}\text { Ketika saya pulang } \\
\text { bermain bersama } \\
\text { teman hingga larut } \\
\text { maalam ayah selalu } \\
\text { memarahi saya dan } \\
\text { menampar hingga } \\
\text { memukul badan } \\
\text { saya. }\end{array}$ & $\begin{array}{l}\text { Marah : } 90 \% \\
\text { Kecewa : } 78 \%\end{array}$ & $\begin{array}{l}\text { Pasti ayah } \\
\text { menganggap } \\
\text { saya adalah anak } \\
\text { yang nakal } \\
\text { karena selalu } \\
\text { bermain hingga } \\
\text { larut malam }\end{array}$ & $\begin{array}{lr}\text { Mungkin ayah } \\
\text { memberikan } \\
\text { tamparan dan } \\
\text { pukulan agar saya } \\
\text { menjadi anak } \\
\text { yang lebih baik } \\
\text { dan patuh } \\
\text { terhadap orangtua }\end{array}$ & $\begin{array}{l}\text { Marah : } 35 \% \\
\text { Kecewa : } 40 \%\end{array}$ \\
\hline $\begin{array}{l}\text { Ketika } r \text { saya } \\
\text { bercerita kepada } \\
\text { ayah, ayah tidak } \\
\text { menanggapi yang } \\
\text { saya ceritakan dan } \\
\text { hanya terdiam }\end{array}$ & $\begin{array}{l}\text { Cemas: } 85 \% \\
\text { Marah : } 65 \%\end{array}$ & $\begin{array}{l}\text { Ayah pasti } \\
\text { masih marah } \\
\text { karena perilaku } \\
\text { saya yang tetap } \\
\text { pulang bermain } \\
\text { selalu hingga } \\
\text { larut malam }\end{array}$ & $\begin{array}{l}\text { Mungkin ayah } \\
\text { memperlakukan } \\
\text { saya seperti itu agar } \\
\text { saya lebih } \\
\text { berpikirnya lebih } \\
\text { dewasa dan tidak } \\
\text { selalu mengulangi } \\
\text { kesalahan yang } \\
\text { pernah dilakukan. }\end{array}$ & $\begin{array}{l}\text { Cemas: } 52 \% \\
\text { Marah: } 30 \%\end{array}$ \\
\hline $\begin{array}{l}\text { Ayah selalu } \\
\text { membanding- } \\
\text { bandingkan saya } \\
\text { dengan kakak tiri } \\
\text { saya yang baik dan } \\
\text { selalu patuh kepada } \\
\text { orangtuanya }\end{array}$ & $\begin{array}{l}\text { Marah : } 93 \% \\
\text { Kecewa : } 85 \%\end{array}$ & $\begin{array}{l}\text { Ayah pasti lebih } \\
\text { sayang terhadap } \\
\text { kakak tiri saya } \\
\text { dibandingkan } \\
\text { dengan saya } \\
\text { yang selalu tidak } \\
\text { patuh terhadap } \\
\text { orangtua }\end{array}$ & $\begin{array}{l}\text { Mungkin ayah } \\
\text { membandingkan } \\
\text { saya dengan kakak } \\
\text { tiri agar saya } \\
\text { mampu berfikir } \\
\text { untuk berperilaku } \\
\text { menjadi anak yang } \\
\text { lebih baik }\end{array}$ & $\begin{array}{l}\text { Marah : } 45 \% \\
\text { Kecewa : } 30 \%\end{array}$ \\
\hline
\end{tabular}




\begin{tabular}{|c|l|l|l|r|}
\hline SHARE: SOCIAL WORK JURNAL & VOLUME: 6 & NOMOR: 2 & HALAMAN: $154-272$ & $\begin{array}{r}\text { ISSN:2339 -0042 }(p) \\
\text { ISSN: } 2528-1577(e)\end{array}$ \\
\hline
\end{tabular}

\begin{tabular}{|c|c|c|c|c|}
\hline $\begin{array}{lr}\text { Guru selalu marah } \\
\text { terhadap } \\
\text { ketika di } \\
\text { dan } \\
\text { mekolah } \\
\text { renyuruh saya ke } \\
\text { ruangan BK karena } \\
\text { perilaku saya yang } \\
\text { selalu membolos }\end{array}$ & $\begin{array}{l}\text { Kecewa : } 75 \% \\
\text { Malu : } 86 \% \\
\text { Marah : } 90 \%\end{array}$ & $\begin{array}{l}\text { Pasti guru tidak } \\
\text { senang dengan } \\
\text { perilaku saya } \\
\text { dan akan } \\
\text { memberikan } \\
\text { hukuman } \\
\text { terhadap saya }\end{array}$ & $\begin{array}{l}\text { Mungkin guru BK } \\
\text { memperlakukan } \\
\text { saya seperti itu agar } \\
\text { saya berfikirnya } \\
\text { lebih baik dan } \\
\text { bersyukur masih } \\
\text { bisa bersekolah } \\
\text { tidak seperti orang } \\
\text { lain yang sulit } \\
\text { untuk mengakses } \\
\text { pendidikan dan } \\
\text { tentu menjadi anak } \\
\text { yang rajin sekolah } \\
\text { dan patuh terhadap } \\
\text { aturan yang ada di } \\
\text { sekolah }\end{array}$ & $\begin{array}{l}\text { Kecewa : } 45 \% \\
\text { Malu : } 30 \% \\
\text { Marah : } 53 \%\end{array}$ \\
\hline
\end{tabular}

Keterangan :

1. Marah
$>$ Marah sekali
: $65-100 \%$
$>$ Marah biasa
: $45-65 \%$
> Marah sementara
: $1-45 \%$

\section{Cemas}
$>$ Cemas sekali
: $60-100 \%$
$>$ Cemas biasa
: $40-60 \%$
$>$ Cemas sementara
: $1-40 \%$

3. Kecewa
$>$ Kecewa sekali
: $70-100 \%$
$>$ Kecewa biasa
: 40-70\%
$>$ Kecewa sementara
: $1-40 \%$

4. Malu
$>$ Malu sekali
: $70-100 \%$
$>$ Malu biasa
: 40-70\%
$>$ Kecewa sementara
: $1-40 \%$

Setelah seminggu melakukan proses treatment, terlihat perkembangan yang cukup signifikan dalam diri klien. Klien lebih mampu berpikiran positif dan intensitas distorsi kognitif yang klien alami selama proses tretment semakin hari semakin menurun. Klien juga telah mampu mengganti kesalahan cara berpikirnya (distorsi kognitif) dengan pikiran-pikiran yang lebih positif. 
Simpulan dnn Saran (Conclusion and Suggestion)

Pada praktikum ini praktikan belajar sebagai pendamping klien yang mempunyai masalah distorsi kognitif atau kesalahan cara berpikir. Masalah tersebut diakui klien sejak masuk SMA, klien mengira masalah tersebut tidak memengaruhi atau berdampak pada perilaku dan kegiatan klien. Tapi, setelah proses pendampingan dengan praktikan, klien sadar masalah tersebut telah mempengaruhi proses berpikirnya sehingga berdampak pada tiap hal yang ia lakukan. Kemudian dapat mengganggu terhadap kehidupan seseorang dan juga akan berpengaruh terhadap beragam aktivitasnya dan berdampak pada perilakunya.

Tahapan-tahapan selama praktikum mikro ini praktikan mulai dari proses kontak awal dengan klien, kemudian pendekatan dengan klien atau kontak dan melakukan kontrak pendampingan dengan klien. Tahap selanjutnya dengan mencari informasi tentang klien sampai menemukan masalah-masalah yang terjadi di diri klien. Selanjutnya merumuskan mengenai permasalahan yang dihadapi dan cara mengatasinya. Kemudian dilanjutkan dengan melakukan assessment, plan of treatment, treatment, terminasi, dan evaluasi. Karena permasalahan yang dihadapi klien ada pada distorsi kognitif, maka tahapan selanjutnya praktikan menggunakan Cognitif Therapi yaitu metode Cognitif Restructuring Form (CRF) lima kolom dalam proses treatment.
Selama proses pendampingan berlangsung klien sangat antusias untuk mengikuti rangkaian proses pendampingan tersebut karena setelah klien menyadari masalah distorsi kognitifnya, klien bertekad untuk mengatasi masalahnya tersebut. Klien sadar apabila masalah ini tidak segera diselesaikan maka akan sangat berpengaruh terhadap kehidupannya. Setelah proses treatment dilakukan, klien terlihat mengalami perkembangan yang cukup baik. Setelah proses treatment yang dilakukan dengan metode Cognitive Restructuring Form, klien mengaku telah mampu melatih dirinya sendiri untuk mengurangi distorsi kognitifnya. Klien juga saat ini telah mampu memandang segala sesuatu dari sisi positif, meskipun kadang kala klien juga berpikiran negatif. Namun. ketika ia berpikiran negatif, ia secara langsung mampu mengubah pikiran negatifnya tersebut dengan pikiran positif yang lebih positif.

Dalam proses pendampingan ini, praktikan mememukan bahwa klien memiliki banyak potensi yang dapat ia kembangkan. Maka sangat disayangkan apabila potensi yang klien miliki terbuang begitu saja akibat pikiran negatif yang dimiliki klien. Terlebih klien mempunyai potensi dalam olahraga sepakbola. Maka potensi yang klien miliki harus dikembangkan sebaik mungkin. Praktikan memberikan saran kepada klien untuk lebih mengembangkan, memanfaatkan dan mengoptimalkan potensi apapun yang dimiliki 
klien karena hal tersebut dapat menjadi

pendukung kesuksesan klien di masa depan.

\section{DAFTAR PUSTAKA}

Dahar, Ratna Wilis. 2011. Teori-Teori Belajar \& Pembelajaran. Jakarta: Erlangga
Fian, Arie(2010). Teori kognitif

Kartono, Kartini. 1988. Psikologi Remaja. Bandung : PT. Rosda Karya.

Stenberg, Robert J. 2008. Psikologi Kognitif Edisi Keempat. Yogyakarta: Pustaka pelajar 